Article

\title{
Electromechanical Dynamics Model of Ultrasonic Transducer in Ultrasonic Machining Based on Equivalent Circuit Approach
}

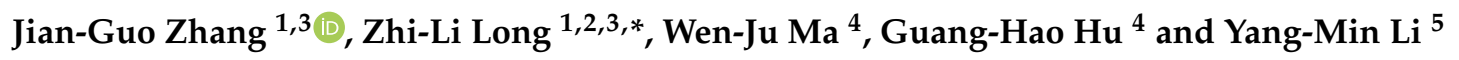 \\ 1 Harbin Institute of Technology Shenzhen, Shenzhen 518055, China; zhangjianguohit@foxmail.com \\ 2 Key Laboratory of Precision Microelectronic Manufacturing Technology \& Equipment of Ministry of \\ Education of Guangdong University of Technology, Guangzhou 510006, China \\ 3 Shenzhen Engineering Lab for Medical Intelligent Wireless Ultrasonic Imaging Technology, \\ Shenzhen 518055, China \\ 4 Henan University of Science and Technology, Luoyang 471003, China; m1468934516@126.com (W.-J.M.); \\ huguanghaohenan@foxmail.com (G.-H.H.) \\ 5 The Hong Kong Polytechnic University, Kowloon, Hong Kong, China; yangmin.li@polyu.edu.hk \\ * Correspondence: longzhili@hit.edu.cn; Tel.: +86-135-1028-1931
}

Received: 31 January 2019; Accepted: 20 March 2019; Published: 21 March 2019

\begin{abstract}
Ultrasonic transducer is a piezoelectric actuator that converts AC electrical energy into ultrasonic mechanical vibration to accelerate the material removal rate of workpiece in rotary ultrasonic machining (RUM). In this study, an impedance model of the ultrasonic transducer is established by the electromechanical equivalent approach. The impedance model not only facilitates the structure design of the ultrasonic transducer, but also predicts the effects of different mechanical structural dimensions on the impedance characteristics of the ultrasonic transducer. Moreover, the effects of extension length of the machining tool and the tightening torque of the clamping nut on the impedance characteristics of the ultrasonic transducer are investigated. Finally, through experimental analysis, the impedance transfer function with external force is established to analyze the dynamic characteristics of machining process.
\end{abstract}

Keywords: impedance model; equivalent circuit; ultrasonic transducer; rotary ultrasonic machining (RUM)

\section{Introduction}

Super hard materials have been applied in many fields, including medical, electronic product, industry equipment, and aeronautic technology fields [1-3]. Typical super hard materials include the optical glass, quartz, glass ceramics, corundum, silicon nitride, and composite materials [2,4]. Rotary ultrasonic machining (RUM) can provide the superposition of tool rotation and ultrasonic vibration on the workpiece. With the novel RUM technology, the super hard materials that are difficult to process in traditional way can be processed economically and achieve the better machining quality $[4,5]$.

The ultrasonic vibration system of RUM consists of the power supply, contactless transformer and ultrasonic transducer. The power supply provides AC excitation current to the piezoelectric ceramic stacks, which is based on anti-piezoelectric effect to generate mechanical ultrasonic vibration. The contactless transformer is an electromagnetic induction component to transfer the AC excitation power to ultrasonic transducer through the air-gap. The ultrasonic transducer consists of piezoelectric ceramic stacks, solid horn, collet, clamping nut, and machining tool. The function of the solid horn is to enlarge the mechanical vibration, and to concentrate the ultrasonic energy on the smaller area. The machining tool transmits ultrasonic vibration to the surface of the workpiece. Many investigations have proven 
that the stability of ultrasonic vibration is a critical factor of ultrasonic machining [6-11]. The impedance characteristics of ultrasonic transducers depend on various factors, including the structure materials, the tightness of clamping nut, extension length of the machining tool, and machining force. Therefore, the ultrasonic transducer needs the precise impedance model to describe the ultrasonic transducer and obtain optimized ultrasonic vibration. It is significant to investigate the reliable impedance equivalent model to predict and control the machining process in RUM.

The structural design and dynamics analysis of the ultrasonic transducer have aroused general concern by many researchers and manufacturers. Currently, the modeling methods of the ultrasonic transducer include finite-element analysis, mass-spring-damper (MSD) system, transfer matrices, and equivalent circuits [6-14]. The finite element method (FEM) can attain the vibration modal and the resonant frequency of mechanical structure animatedly. It is commonly used to design and analyze ultrasonic transducers and is always applied to the analysis of dynamic characteristic and resonant frequency of the ultrasonic transducer [6-12]. The FEM can analyze the effect of different structures on the dynamic characteristic of the ultrasonic transducer by setting FEM nodes. Therefore, only the mechanical behavior of the ultrasonic transducer design can be accurately estimated by this method, and it cannot analyze the loss of electrical and external mechanical load. The ultrasonic transducer also can be modeled as a chain of the mass-spring-damper system. Saleem proposed a model based on Kelvin-Voigt model to describe one-dimensional contact interaction between the ultrasonic transducer and workpiece [13]. Voronina and Babitsky investigated a two-order equivalent MSD system to describe the piezoelectric transducer and presented that the contact interface is equivalent to nonlinear load. This equivalent electrical and mechanical system could explain the dynamics of machining process [14,15]. Wang et al. investigated the MSD system to analyze the dynamic characteristics of a thickness-mode piezoelectric transducer at its resonant frequency [16]. The analytical solution and the KLM and Mason's equivalent circuit were investigated to produce identical impedance curves [17]. The equivalent circuit method of the ultrasonic transducer can precisely define the relationship between the electrical input and the mechanical vibration output under defined operating conditions, which rely on an accurate model of the interaction between the electrical and mechanical parameters of the ultrasonic transducer. To obtain an accurate model of ultrasonic transducer, many researchers have studied various equivalent circuit methods. Smyth investigated an analytical Mason equivalent circuit to describe the ultrasonic transducer and enable straightforward and wide-ranging model implementation for future ultrasonic transducer design and optimization [18]. Je et al. developed an advanced equivalent circuit model for the piezoelectric ultrasonic transducer; this model can be used to predict the effect of a piezoelectric layer on the coupling factor and efficiency of piezoelectric micromachined ultrasonic transducers [19]. Caronti et al. developed an accurate model for ultrasonic transducers [20]. Wang et al. presented the design of high-frequency ultrasonic transducers by using electromechanical equivalent method and three-dimensional (3-D) FEM to get the optimization geometric dimensions [21]. The equivalent circuit method can analyze the different mechanical loads, the resonant frequency, and the displacement of an ultrasonic transducer [22-24]. In the above research, the effects of tightness of clamping nut and extension length of machining tool, and the dynamical impedance model with different loads in numerical calculation were not mentioned. In the ultrasonic transducer vibration system, the clamping nut is a critical component to fix the machining tool. The fasten force of clamping nut influences the stress distribution and impedance characteristics of ultrasonic transducer. It is necessary to investigate the tightening torque effect of clamping nut. The machining tool's extension length affects the wavelength distribution of solid horn structure. The different tools' extension lengths need to be considered in assembling machining tool of ultrasonic transducer. Impedance and resonant frequency are key factors in the ultrasonic transducer vibration system. The contributions of this paper are: (1) We investigate the whole electromechanical characteristics of ultrasonic transducer by using the equivalent circuit to describe the lumped static impedance/admittance characteristic of ultrasonic transducer, (2) The ultrasonic piezoelectrical transducer is sensitive to the external mechanical load [25]. Therefore, the 
dynamical impedance transfer function of ultrasonic transducer with different loads is established by the parameter fitting method. Through this modelling method, the resonant frequency and impedance can be beneficial to the monitoring of machining process. In this paper, the impedance lumped model of ultrasonic transducer can calculate and predict the static and dynamic impedance characteristics of an ultrasonic transducer.

The paper is organized into six sections. Section 1 presents the introduction. In Section 2, the mechanical structure is introduced. In Section 3, the impedance equivalent circuit method is applied to impedance modeling of ultrasonic transducer. Section 4 establishes the experimental platform to verify the effect of clamping nut and machining tool extended length. The static impedance model is verified by the experimental measurement. In Section 5, The MSD and electrical models are utilized to describe the ultrasonic transducer vibration system, the impedance transfer function with external force is established to analyze the dynamic characteristic of machining process. Finally, the conclusions are presented in Section 6.

\section{Mechanical Structure of Ultrasonic Transducer}

Figure 1 shows the typical structure of the solid horn-type piezoelectric transducer. Generally, the ultrasonic transducer consists of eight main parts, including the inner screw bolt, the back slab, the piezoelectric ceramic stacks, the front slab, clamping nut, collet tool, solid horn, and machining tool. The piezoelectric ceramic stacks are clamped between the front slab and back slab. The determination of horn structure resonant wavelength usually integer multiple of half wavelength [26]. The ultrasonic vibration is realized by using the piezoelectric ceramics converts electrical energy into mechanical energy based on anti-piezoelectric effect $[27,28]$. This vibration amplitude of piezoelectric ceramics is still small, so the vibration of piezoelectric ceramic stacks is amplified by the horn structure. The machining tool is clamped to the head of solid horn with threaded connection of the clamping nut. The ultrasonic transducer is driven by the electric sinusoidal waveforms from an ultrasonic generator with resonant frequency tracking. Then ultrasonic mechanical vibration is applied to the workpiece.

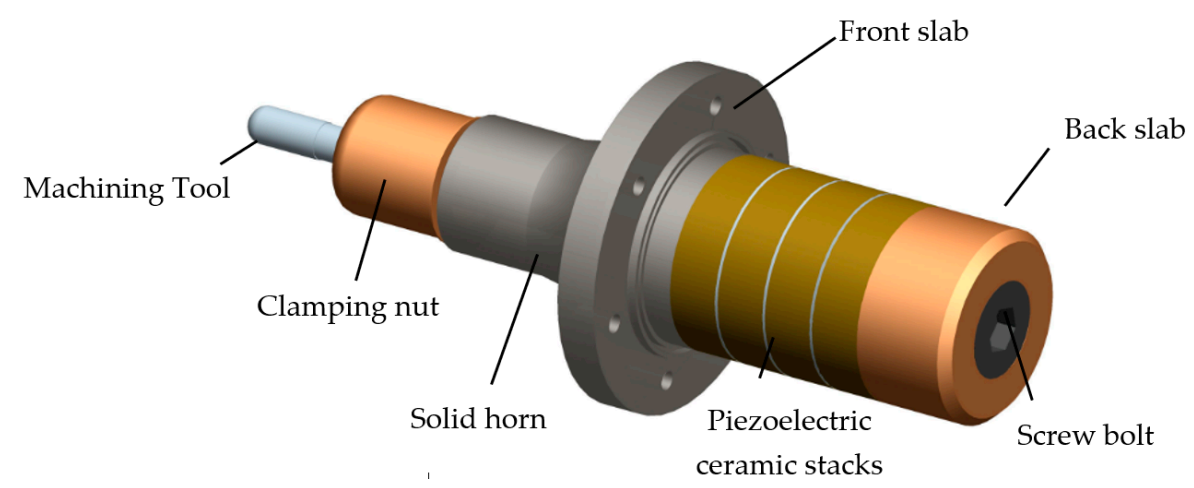

Figure 1. Mechanical structure of ultrasonic transducer.

\section{Impedance Modeling}

\subsection{The piezoelectric Ceramic Stacks and Screw Bolt}

The electromechanical equivalent method is an effective way to deal with ultrasonic transducer design [22,29]. In the equivalent circuit, $C_{0}$ is the piezoelectric capacitance of the transducer. In detail, the mechanical force is equal to voltage, and the vibration velocity is equal to current. Therefore, the electromechanical equivalent circuit of piezoelectric stacks and screw bolt is shown in Figure 2 . The electromechanical equivalent circuit of ultrasonic transducer is obtained by separating the piezoelectric material into an electrical port and a mechanical port by using an ideal electromechanical transformer. $\mathrm{N}$ is piezoelectric coupling factor and $\mathrm{N}<1$. The screw bolt and piezoelectric ceramic 
stacks are labelled as $\mathrm{S}$ and $\mathrm{P}$, respectively. Subscripts $\mathrm{L}, \mathrm{M}$, and $\mathrm{R}$ denote the left, middle and right location of T-type equivalent impedance structure.

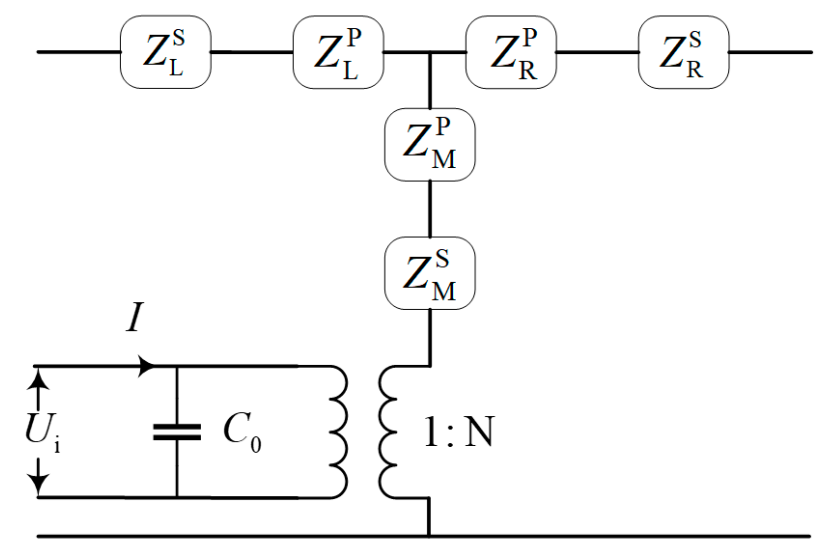

Figure 2. The equivalent circuit of the piezoelectric stack and screw bolt.

The static capacitance value of piezoelectric ceramic stacks is expressed by:

$$
C_{0}=n \frac{d_{33}}{s_{33}^{E}} \frac{S}{t}
$$

where $s_{33}^{\mathrm{E}}$ is the elastic compliance, $d_{33}$ is the piezoelectric charge coefficient, $S$ is the area of piezoelectric ring, and the area of the stack is $S=\pi\left(r_{2}^{2}-r_{1}^{2}\right) . t$ is thickness of the piezoelectric ring and $n$ is the number of piezoelectric rings [22,29]. The piezoelectric coupling factor $N$ is expressed as:

$$
N=\frac{n S}{L_{\mathrm{P}}} \frac{d_{33}}{s_{33}^{\mathrm{E}}}
$$

where the total length of the piezoelectric stacks and the screw bolt is $L_{\mathrm{P}}=n t$.

The Equivalent impedances of screw bolt and piezoelectric stacks are expressed as:

$$
\begin{aligned}
Z_{\mathrm{R}}^{\mathrm{S}}=Z_{\mathrm{L}}^{\mathrm{S}} & =j Z_{0}^{\mathrm{S}} \tan \left(\frac{\tau^{\mathrm{S}} L_{\mathrm{P}}}{2}\right) \\
Z_{\mathrm{R}}^{\mathrm{P}}=Z_{\mathrm{L}}^{\mathrm{P}} & =j Z_{0}^{\mathrm{P}} \tan \left(\frac{\tau^{\mathrm{P}} L_{\mathrm{P}}}{2}\right) \\
Z_{\mathrm{M}}^{\mathrm{S}} & =\frac{Z_{0}^{\mathrm{S}}}{j \sin \left(\tau^{\mathrm{S}} L_{\mathrm{P}}\right)} \\
Z_{\mathrm{M}}^{\mathrm{P}} & =\frac{Z_{0}^{\mathrm{P}}}{j \sin \left(\tau^{\mathrm{P}} L_{\mathrm{P}}\right)}
\end{aligned}
$$

where $Z_{0}^{\mathrm{i}}=\rho c S$ is the specific acoustic impedance which is the product of the density, velocity and area of the piezoelectric ring or the screw bolt. $\tau^{\mathrm{i}}=\omega / c$ is the material propagation constant, and $c$ is the material acoustic velocity.

\subsection{The Solid Horn Structures}

The electromechanical equivalent equations of the solid horn can be expressed as a T-type equivalent circuit $[22,23,29]$, and the equivalent impedance expressions of the two horn structures are shown in Table 1. 
Table 1. Impedance of the horn structure in the analytical model.

\begin{tabular}{lll}
\hline Type & Parameters & Equations \\
\hline Constant horn & $\begin{array}{c}S=S_{1}=S_{2} \\
S_{1} \text { and } S_{2} \text { are the area of } \\
\text { front and back section. } \\
L \text { is the horn length. }\end{array}$ & $\begin{array}{l}Z_{\mathrm{L}}=Z_{\mathrm{R}}=\rho c S\left(\frac{1}{j \tan (\tau L)}-\frac{1}{j \sin (\tau L)}\right) \\
Z_{\mathrm{M}}=\frac{\rho c}{j \sin (\tau L)}\end{array}$ \\
\hline
\end{tabular}

\subsection{The Tightening Torque of Clamping Nut}

The wave speed in the material is determined by the stress and elongation. The relationship between the wave speed and the bolt elongation is formulated and utilized to develop a real-time ultrasonic control of the tightening process of bolted assemblies [30]. The clamping nut and collet tool are constructed into fastening the machining tool. They can be taken as a rigid constant section horn. The fasten force can impact the ultrasonic wave velocity of the threaded components.

The wave speed of material varies with fasten force. When the longitudinal ultrasonic wave propagates in the uniform material and regular shape object, it is affected by the axial stress of object [30,31]. The relational expression is as follows:

$$
\frac{d c_{\mathrm{n}}}{d \sigma}=\frac{\left[2 l+\lambda+\left(\frac{\lambda+\mu}{\mu}\right)(4 m+4 \lambda+10 \mu)\right]}{2 c_{\mathrm{n}} \rho(3 \lambda+2 \mu)}
$$

where $\lambda$ and $\mu$ are Lamé or second-order elastic constants, $l$ and $m$ are Murnaghan's third-order elastic constants, $\rho$ is the material density, $c_{\mathrm{n}}$ is wave speed, and $\sigma$ is the compressive stress.

The wave speed is determined by the tightening torque of clamping nut and the material properties. In the elastic range, the wave speed with the axial elongation $\Delta l$ is expressed as:

$$
c_{\mathrm{n}}=\left(c_{o}^{2}+\Lambda(\Delta l / L)\right)^{\frac{1}{2}}
$$

The clamping nut, collet tool and machining tool can be regarded as uniform and isotropic material column. The equivalent impedance expressions are:

$$
\left\{\begin{array}{l}
Z_{\mathrm{R}}^{\mathrm{C}}=Z_{\mathrm{L}}^{\mathrm{C}}=\rho_{c} \mathcal{C}_{\mathrm{n}} S_{\mathrm{c}}\left(\frac{1}{j \tan \left(\tau_{c} L_{c}\right)}-\frac{1}{j \sin \left(\tau_{c} L_{c}\right)}\right) \\
Z_{\mathrm{M}}^{\mathrm{C}}=\frac{\rho_{c} \mathcal{C}_{\mathrm{S}} \mathcal{C}_{\mathcal{c}}}{j \sin \left(\tau_{c} L_{c}\right)}
\end{array}\right.
$$

\subsection{Impedance Equivalent Modeling}

From individual equivalent circuit and their corresponding impedance, the whole equivalent circuit for the ultrasonic transducer is integrated as Figure 3. The input impedance of the back slab, front slab, clamping nut, and machining tool which are constant for their cross-section area, are defined as constant horn. The input impedance of the solid horn is defined as the exponential horn. 


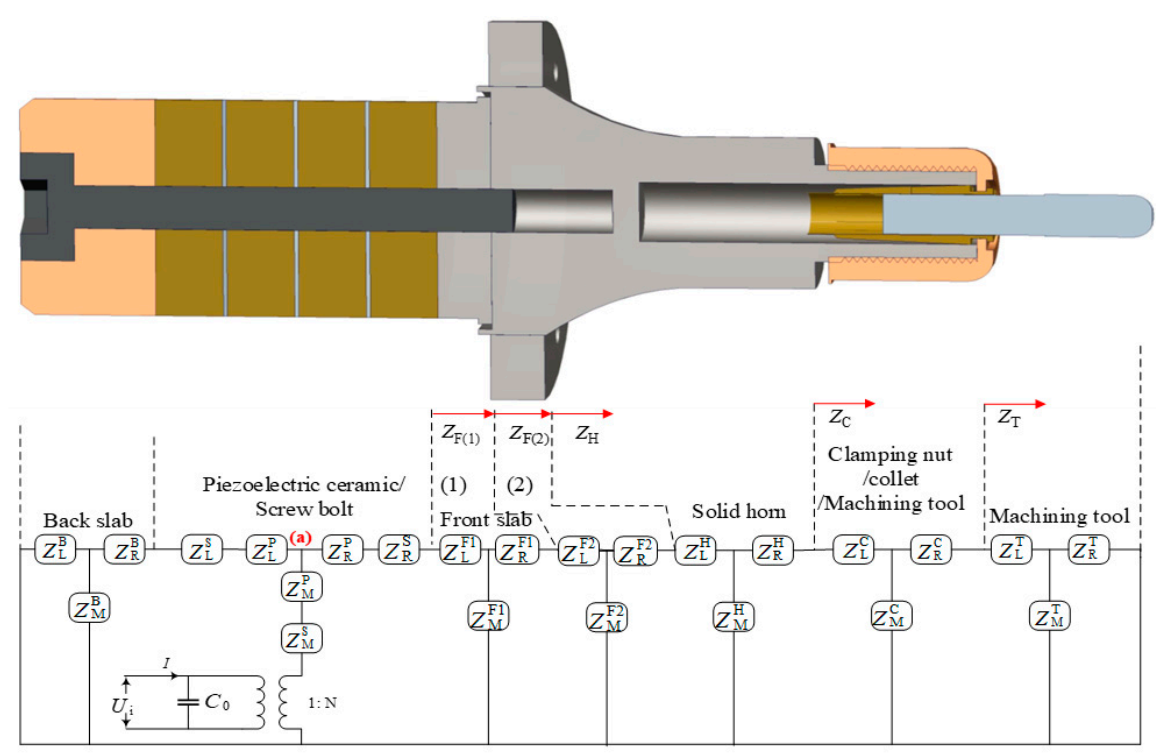

Figure 3. The equivalent circuit model of the ultrasonic transducer.

Based on the Table 1, the equivalent impedance of the front slab (1) is:

$$
\mathrm{Z}_{\mathrm{F}(1)}=\mathrm{Z}_{\mathrm{L}}^{\mathrm{F}}+\frac{\mathrm{Z}_{\mathrm{M}}^{\mathrm{F}} \times\left(\mathrm{Z}_{\mathrm{R}}^{\mathrm{F}}+\mathrm{Z}_{\mathrm{F}(2)}\right)}{\mathrm{Z}_{\mathrm{M}}^{\mathrm{F}}+\left(\mathrm{Z}_{\mathrm{R}}^{\mathrm{F}}+\mathrm{Z}_{\mathrm{F}(2)}\right)}
$$

Similarly, the input equivalent impedance $\mathrm{Z}_{\mathrm{C}}, \mathrm{Z}_{\mathrm{H}}, \mathrm{Z}_{\mathrm{F}(2)}$ in Figure 3 can be expressed in the same formula form. Then, the equivalent impedance of right side of location (a) in Figure 3 is shorted as:

$$
Z_{\text {right }}=Z_{R}^{P}+Z_{R}^{S}+Z_{F(1)}
$$

Similarly, the equivalent impedance of left side of location (a) in Figure 3 is:

$$
Z_{\text {left }}=Z_{L}^{P}+Z_{L}^{S}+Z_{R}^{B}+\frac{Z_{L}^{B} \times Z_{M}^{B}}{Z_{L}^{B}+Z_{M}^{B}}
$$

Therefore, the total mechanical impedance of the horn is:

$$
Z_{m}=Z_{M}^{S}+Z_{M}^{P}+\frac{Z_{\text {right }} \times Z_{\text {left }}}{Z_{\text {right }}+Z_{\text {left }}}
$$

The electromechanical equivalent impedance of the ultrasonic transducer is expressed as:

$$
Z_{\mathrm{e}}=\frac{1}{Y_{\mathrm{e}}}=\frac{U}{I}=\frac{Z_{\mathrm{C}_{0}} \times N^{2} Z_{\mathrm{m}}}{Z_{\mathrm{C}_{0}}+N^{2} Z_{\mathrm{m}}}
$$

where $Z_{\mathrm{C}_{0}}=1 / j \omega C_{0}, Y_{\mathrm{e}}$ is admittance, and $N$ is the coupling factor defined in Equation (2).

Therefore, the electrical impedance model of the ultrasonic transducer vibration system is established as Equation (14). This lumped equivalent impedance/admittance model includes all parameters, including wave speed and the density of material, the mechanical and electrical losses in material and the structural dimensions.

\section{Numeral Calculation and Discussion}

From the established impedance model, the frequency and impedance of the ultrasonic transducer at different loads are calculated in MATLAB. The properties of the ultrasonic transducer are listed in 
Table 2, and the material loss can be defined as imaginary part in the elastic module [29]. In experiment, the impedance of the ultrasonic transducer is measured frequency sweeping by using an Agilent 4294A impedance analyzer. The axial force testing platform is established by the Z-axis motor motion structure, the motor driver (model ATK-2MD4850), the force sensor (model FB10-100 kg), and the data acquisition device (model JL-DT01). This platform can realize the identification of dynamic impedance model of ultrasonic transducer with axial force. The experimental platform is shown in Figure 4.

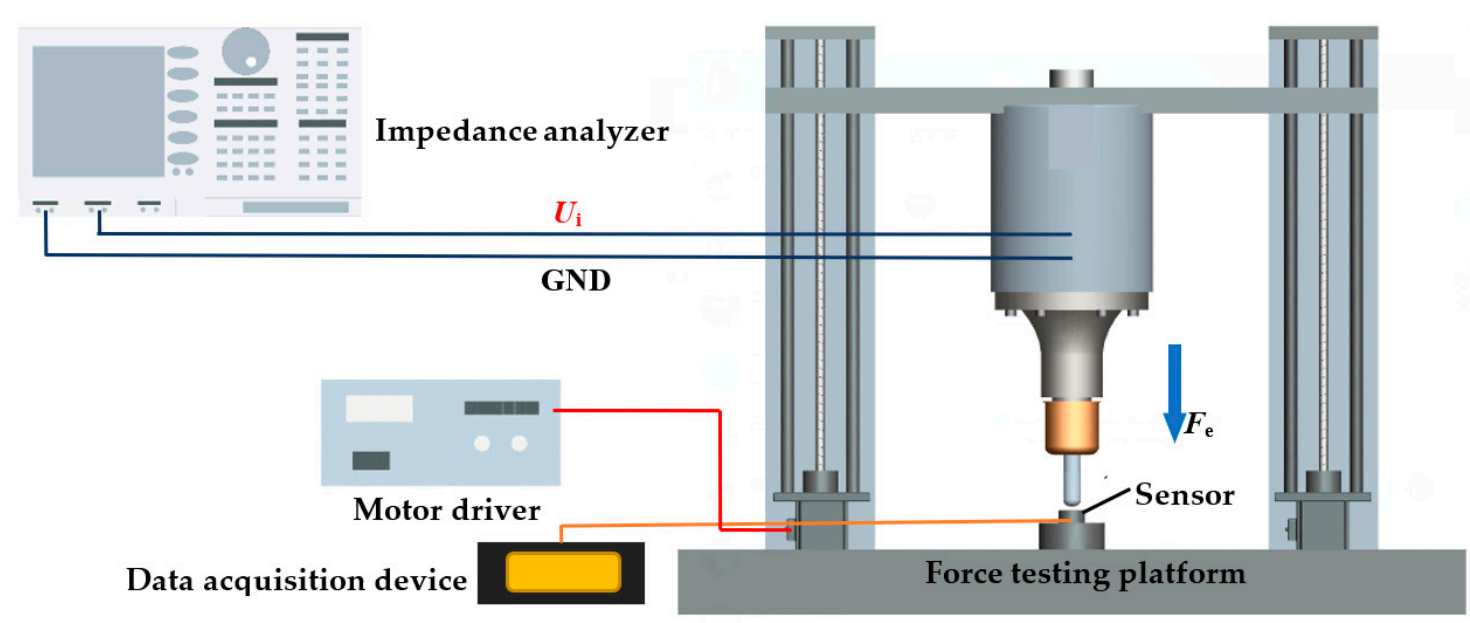

Figure 4. The experimental platform.

Table 2. Properties of the ultrasonic transducer in the analytical model.

\begin{tabular}{|c|c|c|c|c|c|c|}
\hline & \multirow{2}{*}{ Type } & \multirow{2}{*}{$\begin{array}{l}\text { Density } \\
\left(\mathrm{kg} \cdot \mathrm{m}^{-3}\right)\end{array}$} & \multirow{2}{*}{$\begin{array}{l}\text { Poisson } \\
\text { Ratio }\end{array}$} & \multicolumn{2}{|c|}{ Dimensions } & \multirow{2}{*}{ Other Parameters } \\
\hline & & & & Diameter (mm) & Length (mm) & \\
\hline $\begin{array}{l}\text { Piezoelectric } \\
\text { Ring }\end{array}$ & PZT-4 & 7700 & 0.25 & $\begin{array}{l}\text { Outer:32.0 } \\
\text { Inner:13.9 }\end{array}$ & 6 & $\begin{array}{c}\mathrm{d}_{33}=270(1-0.0003 \mathrm{i}) \mathrm{pC} / \mathrm{N} \\
\mathrm{S}_{\mathrm{E}}^{33}=2 \times 10^{11}(1-0.0012 \mathrm{i}) \mathrm{m}^{2} / \mathrm{N}\end{array}$ \\
\hline Screw bolt & \multirow{5}{*}{$\begin{array}{l}\text { Stainless } \\
\text { steel }\end{array}$} & \multirow{5}{*}{7930} & \multirow{5}{*}{0.28} & 13.5 & 36.5 & \multirow{5}{*}{$\mathrm{E}=2.15 \times 10^{11}(1+0.001 \mathrm{i}) \mathrm{N} / \mathrm{m}^{2}$} \\
\hline Back slab & & & & 32.0 & 10.8 & \\
\hline Exponential horn & & & & $\mathrm{S}_{1}: 28.2 \mathrm{~S}_{\mathrm{e}}: 22.1$ & 27.8 & \\
\hline Clamping nut & & & & 17.1 & 15.2 & \\
\hline Machining tool & & & & 6.0 & $\begin{array}{l}\left(15^{*}\right) \\
38.7\end{array}$ & \\
\hline
\end{tabular}

* Extension length of machining tool.

\subsection{Load of Ultrasonic Transducer}

When the ultrasonic transducer is loaded with the machining tool, the parameters of materials and structural dimensions based on Table 2 are substituted in Equation (14). The impedance characteristics of ultrasonic transducer are shown in Figure 5. It is found that the corresponding conductance, susceptance and resonant frequency get closed to the experimental measurement results of ultrasonic transducer. When the conductance is at maximum value and the susceptance is zero, the phase of ultrasonic transducer is zero and corresponding impedance of ultrasonic transducer is lowest, the current frequency is the resonant frequency of ultrasonic transducer. When the ultrasonic transducer operates at resonant frequency, the active power of ultrasonic transducer reaches maximum. It means that the electrical equivalent model can accurately describe the ultrasonic transducer in RUM. 


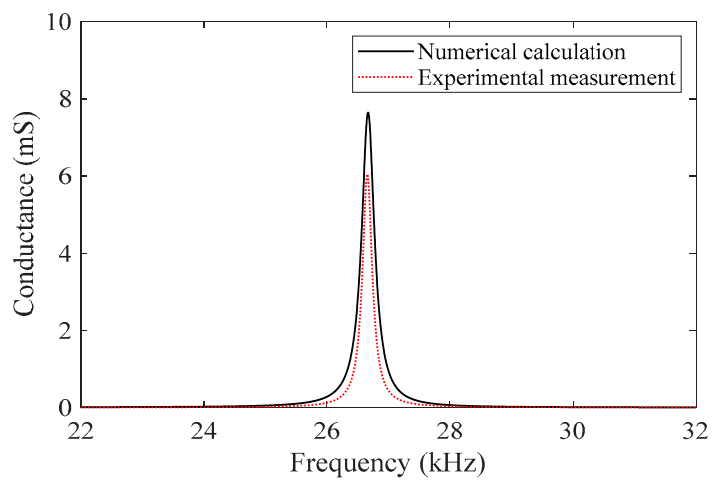

(a)

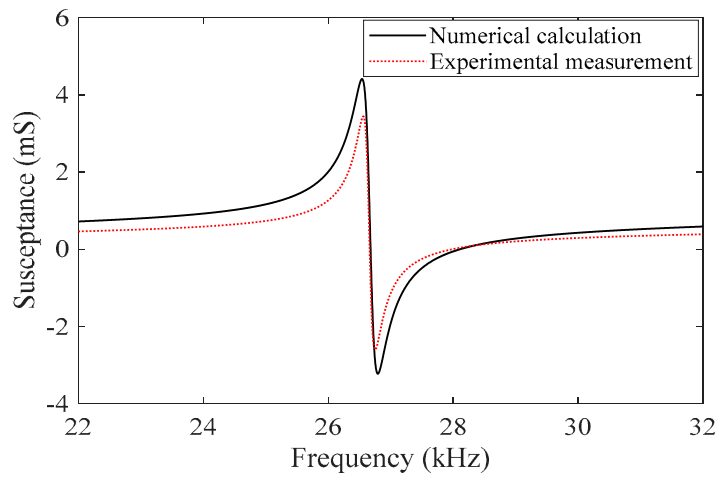

(b)

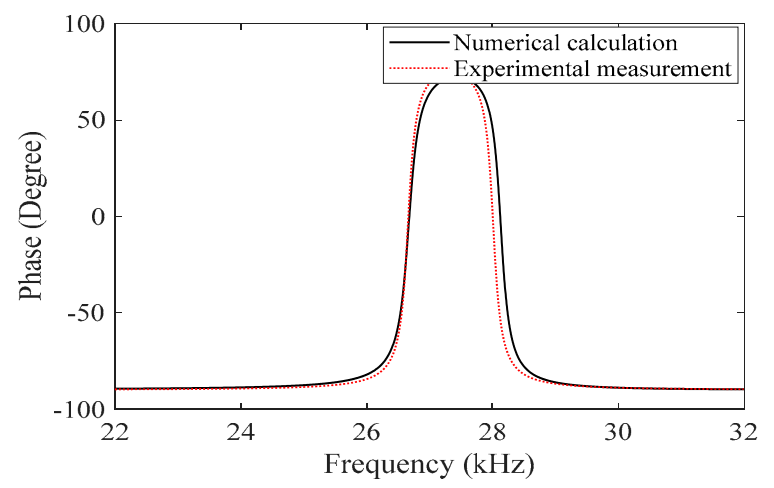

(c)

Figure 5. The impedance characteristics of the ultrasonic transducer. (a) Conductance; (b) Susceptance; (c) Phase.

\subsection{Load with Different Torques of Clamping Nut}

The resonant frequency and impedance characteristics of the ultrasonic transducer with different torques of clamping nut are obtained as shown in Figure 6. The experimental data validates the sound velocity effect on the trend of resonant frequency. It is observed that when the fasten force increases with the tightening torque, the sound velocity increases with the torque. When the tightening torque becomes larger, the resonant frequency of ultrasonic transducer increases, while the corresponding impedance of ultrasonic transducer at the resonant frequency decreases. 


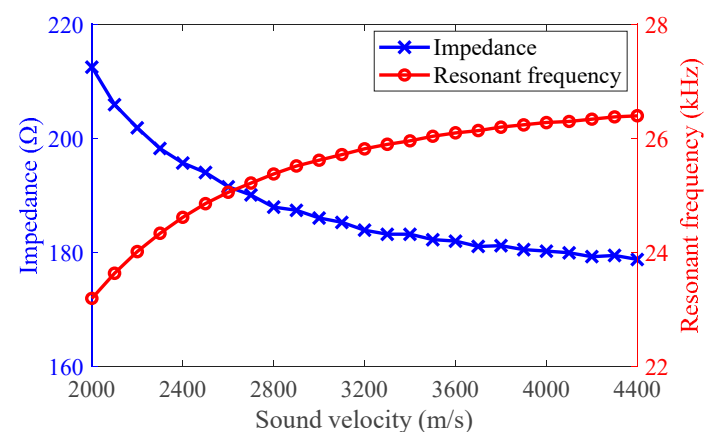

(a)

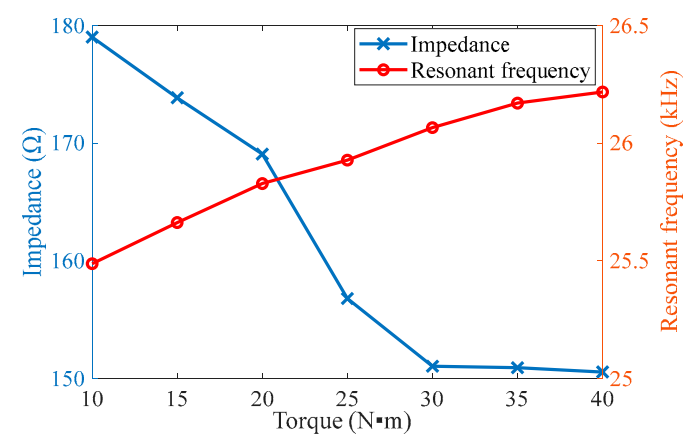

(b)

Figure 6. Resonant frequency and impedance with different sound velocity and tightening torque.

(a) Theoretical calculation; (b) Experimental measurement.

\subsection{Load with Different Extension Lengths of Tool}

When the ultrasonic transducer is in operation, the machining tool wears down due to heat and friction, resulting in poor processing quality of processed object. It is necessary to replace the broken machining tool regularly. In the experiment, the admittance circle and the resonant frequency of ultrasonic transducer are measured by the impedance analyzer. The measurement results are shown in Figure 7. The admittance circle is changed with different extension lengths of machining tool in Figure 7a. It is found that the extension length of machining tool strongly influences the vibration characteristics of ultrasonic transducer. When the extension length of the machining tool becomes longer, the resonant frequency of the ultrasonic transducer decreases (Figure $7 \mathrm{~b}$ ).

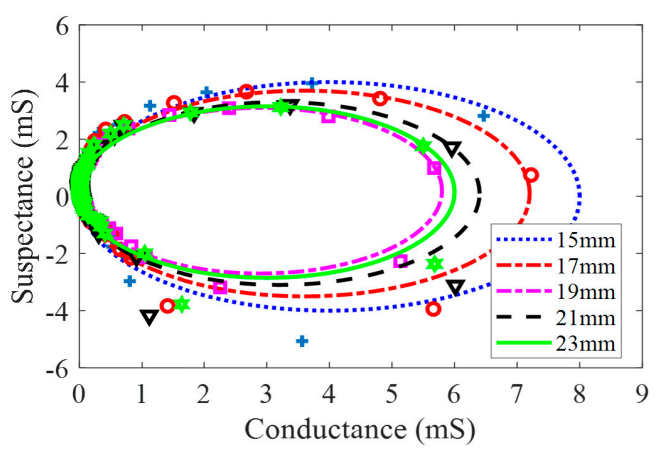

(a)

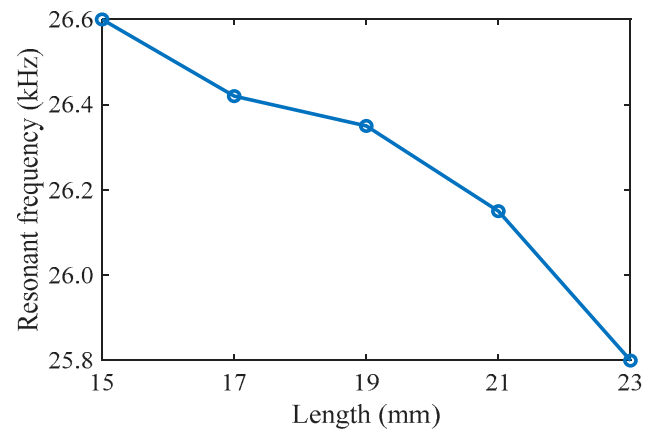

(b)

Figure 7. Admittance circle and resonant frequency with different lengths. (a) Admittance circle; (b) Resonant frequency.

\section{Dynamic Modeling of Ultrasonic Transducer}

When the ultrasonic transducer is in the no-load state, its resonant frequency and impedance do not vary when the extension length of machining tool are fixed. Its impedance model can be taken as constant. In the machining process, the external force is transmitted to the piezoelectric vibrator through the horn and tool, and the internal material electromechanical coefficient varies with the extrusion of axial forces. Therefore, the resonant frequency, impedance, and vibration amplitude of the ultrasonic transducer affect the quality of the machining process. The external force effect can be described by a dynamics simulation model, its equivalent MSD system is shown in Figure 8a. When the ultrasonic power driver provides excitation voltage to the ultrasonic transducer by brass electrodes, the piezoelectric ceramics output the ultrasonic vibration force to push the horn structure. The initialization displacement of piezoelectric ceramics is $x_{0}(\mathrm{t})$, the piezoelectric ceramics part can be taken as one-order MSD system. $M_{\mathrm{p}}$ is the mass of piezoelectric ceramic stacks, $B_{\mathrm{p}}$ and $K_{\mathrm{p}}$ are the damping coefficient and spring rigidity of piezoelectric ceramics, respectively. Furthermore, the 
initialization displacement is amplified by the horn structure. The front slab, back slab, solid horn, clamping nut, collet, and machining tool are another one-order MSD system, $M_{\mathrm{h}}, B_{\mathrm{h}}$, and $K_{\mathrm{h}}$ are the mass, the damping coefficient and spring rigidity of MSD system. Then the vibration displacement is transferred to the workpiece. Based on Mason's rule [16,32], the impedance model of ultrasonic transducer also can be equivalent to electrical equivalent model as shown in Figure $8 \mathrm{~b}$, the $L_{1}$ is the dynamic inductance, $C_{1}$ is the dynamic capacitance, $R_{1}$ is the dynamic resistance of ultrasonic transducer, and $R_{\mathrm{a}}$ is the current sample resistance $\left(R_{\mathrm{a}}<<R_{1}\right)$.

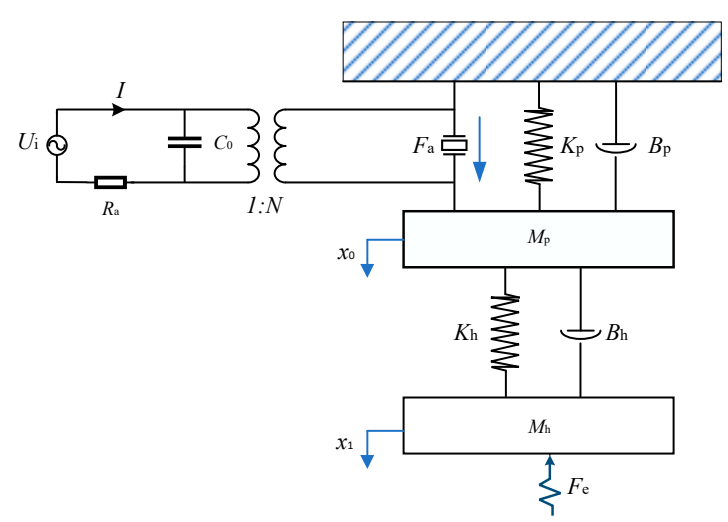

(a)

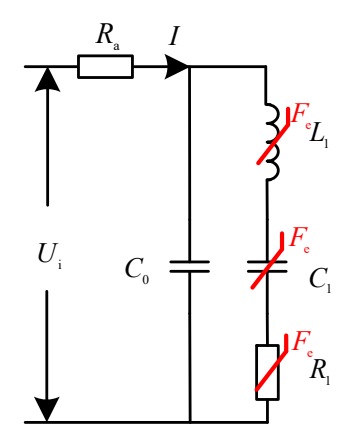

(b)

Figure 8. The equivalent model of ultrasonic transducer. (a) Dynamic MSD equivalent model; (b) Electrical equivalent impedance model.

A dynamics expression of the piezoelectric actuator can be formulated to express the displacement of the piezoelectric ceramics $x_{\mathrm{o}}(\mathrm{t})$; the dynamics function is:

$$
M_{\mathrm{p}} \ddot{x}_{0}=B_{\mathrm{h}}\left(\dot{x}_{1}-\dot{x}_{0}\right)+K_{\mathrm{h}}\left(x_{1}-x_{0}\right)-B_{\mathrm{p}} \dot{x}_{0}-K_{\mathrm{p}} x_{0}+F_{\mathrm{a}}
$$

The $x_{1}(t)$ movement function of the machining tool tip is:

$$
M_{\mathrm{h}} \ddot{x}_{1}=-B_{\mathrm{h}}\left(\dot{x}_{1}-\dot{x}_{0}\right)-K_{\mathrm{h}}\left(x_{1}-x_{0}\right)-F_{\mathrm{e}}
$$

where $F_{\mathrm{e}}$ is the contact force, and $F_{\mathrm{a}}$ is the ultrasonic vibration force.

The magnitude displacement of horn structure is:

$$
G_{M}=\frac{x_{1}}{x_{0}}
$$

The electromechanical impedance transfer function without external force based on Mason's rule $[16,32]$ is expressed as:

$$
G(\mathrm{~s})=\frac{U_{\mathrm{i}}}{I}=\frac{a s^{2}+b s+1}{C_{0} s\left(a s^{2}+b s+c+1\right)}
$$

where $a=\left(G_{\mathrm{M}} M_{\mathrm{h}}+M_{\mathrm{p}}\right) /\left(K_{\mathrm{p}}\right), b=\frac{B_{\mathrm{p}}}{K_{\mathrm{p}}}, c=\frac{N^{2}}{G_{\mathrm{M}} C_{0}}$.

The electrical impedance without external force in Figure $8 \mathrm{~b}$ is expressed as:

$$
Z_{\mathrm{e}}(\omega)=\frac{\left(\omega^{2} L_{1} C_{1}-1\right)-j \omega C_{1} R_{1}}{\omega^{2} C_{0} C_{1} R_{1}+j\left[\omega^{3} L_{1} C_{1} C_{0}-\omega\left(C_{1}+C_{0}\right)\right]}
$$

where $\omega=2 \pi f$ is the angular frequency and $f$ is natural frequency. 
The electrical impedance function is expressed as:

$$
\mathrm{G}(\mathrm{s})=\frac{U}{I}=\frac{L_{1} C_{1} \mathrm{~s}^{2}+R_{1} C_{1} \mathrm{~s}+1}{C_{0} \mathrm{~s}\left(L_{1} C_{1} \mathrm{~s}^{2}+R_{1} C_{1} \mathrm{~s}+\frac{C_{1}}{C_{0}}+1\right)}
$$

It is observed that the dynamics impedance transfer function can be equivalent to the electrical impedance transfer function from Equations (18) and (20). The parameters are set as a $=L_{1} C_{1}, b=R_{1} C_{1}$, $\mathrm{c}=\mathrm{C}_{1} / \mathrm{C}_{0}$.

The state space matrix of ultrasonic transducer without external force is expressed as:

$$
\left[\begin{array}{c}
\frac{d u_{\mathrm{C}_{0}}(t)}{d t} \\
\frac{d i_{L_{1}}(t)}{d t} \\
\frac{d u_{\mathrm{C}_{1}}(t)}{d t}
\end{array}\right]=\left[\begin{array}{ccc}
-\frac{1}{C_{0} R_{\mathrm{a}}} & -\frac{1}{C_{0}} & 0 \\
\frac{1}{L_{1}} & -\frac{R_{1}}{L_{1}} & -\frac{1}{L_{1}} \\
0 & \frac{1}{C_{1}} & 0
\end{array}\right]\left[\begin{array}{c}
u_{\mathrm{C}_{0}}(t) \\
i_{L_{1}}(t) \\
u_{\mathrm{C}_{1}}(t)
\end{array}\right]+\left[\begin{array}{c}
\frac{1}{C_{0} R_{\mathrm{a}}} \\
0 \\
0
\end{array}\right] u_{\mathrm{i}}(t)
$$

where $u_{C_{0}}(t)$ is the voltage of the static capacitance, $i_{L_{1}}(t)$ is the current of equivalent dynamic inductance, and $u_{C_{1}}(t)$ is the voltage of equivalent dynamic capacitance.

Figure 8a shows the MSD dynamic system of ultrasonic transducer. The coupling factor is $N$. The input voltage is set to $U_{\mathrm{i}}$. The current in the closed-loop system is obtained to analyze the vibration amplitude of ultrasonic transducer. The external force is $F_{\mathrm{e}}$. The overall closed-loop transfer function of the ultrasonic transducer is shown in Figure 9.

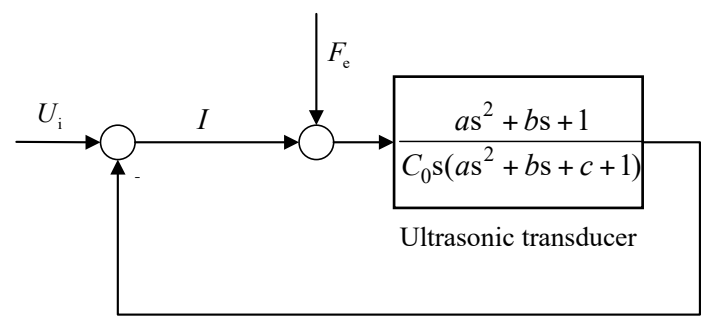

Figure 9. The closed-loop system of ultrasonic transducer.

When the machining tool impacts and separates from the processing interface, the deformation of the piezoelectric ceramic stacks is affected by the contact force. When the ultrasonic transducer is pushed by the Z-axial motion platform structure, the force sensor is as the contact interface to test the axial force. The impedance and phase of the ultrasonic transducer with different axial forces in frequency sweeping are measured by the impedance analyzer are shown in Figure 10. The impedance and phase parameters of ultrasonic transducer provide the data set for overall dynamic and precise impedance modeling. It is found that the resonant frequency $f_{\mathrm{r}}$ and anti-resonant frequency $f_{\mathrm{a}}$ go up with the increase of external force, the corresponding lowest impedance $Z_{\mathrm{r}}$ (resonant frequency) increases and corresponding highest impedance $Z_{a}$ (anti-resonant frequency) decreases. In the machining process, it is investigated that the impedance-frequency characteristics of ultrasonic transducer drastically varies with the external force. 


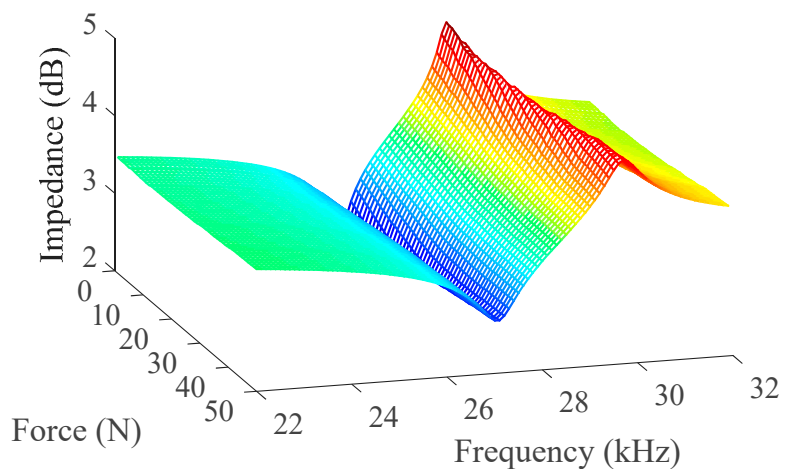

(a)

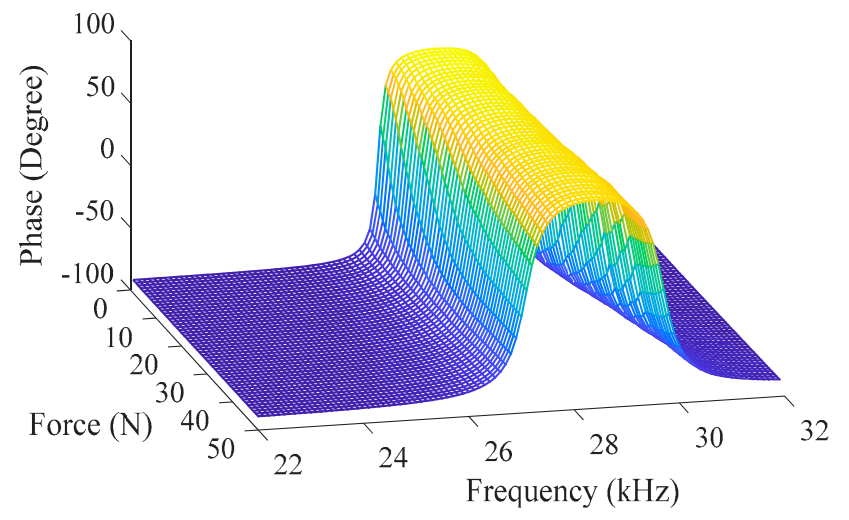

(b)

Figure 10. Impedance and phase with different loads. (a) Impedance; (b) Phase.

The resonant frequency, anti-resonant frequency, and their corresponding impedance are measured by the impedance analyzer. Therefore, the dynamic inductance $L_{1}$, the dynamic capacitance $C_{1}$, the dynamic resistance $R_{1}$, and the static capacitance $C_{0}$ are estimated by the impedance analyzer. To precisely establish the dynamic impedance transfer function, the parameter fitting method is applied in the impedance modeling. The parameters trends with different external forces are calculated and are shown in Figure 11. It is found that when the external force linearly increases, the parameter ' $a$ ' linearly decreases, the parameter ' $b$ ' linearly increases and the parameter ' $c$ ' decreases when external force is less than $11 \mathrm{~N}$ and increases from $11 \mathrm{~N}$ to $50 \mathrm{~N}$. The corresponding fitting functions and corresponding coefficients of determination $\mathrm{R}^{2}$ are listed in Table 3. The parameter fitting functions can meet the fitting accuracy of impedance transfer function of ultrasonic transducer with external force.

Table 3. Parameter fitting Functions and $\mathrm{R}^{2}$.

\begin{tabular}{cccc}
\hline Parameters & Type & Function & $\mathbf{R}^{\mathbf{2}}$ \\
\hline $\mathbf{a}$ & Fourier & $F(x)=a_{0}+a_{1} \cdot \cos (w \cdot x)+b_{1} \cdot \sin (w \cdot x)$ & 0.9983 \\
$\mathbf{b}$ & Polynomial & $F(x)=p_{1} \cdot x+p_{2}$ & 0.9952 \\
$\mathbf{c}$ & Linear Fitting & $F(x)=\alpha \cdot \sin (x-\pi)+\beta \cdot(x-10)^{2}+\delta$ & 0.971 \\
\hline
\end{tabular}




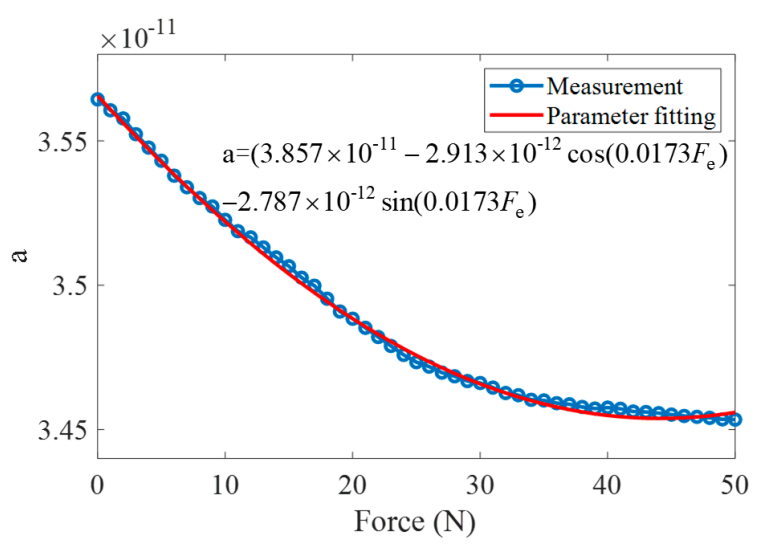

(a)

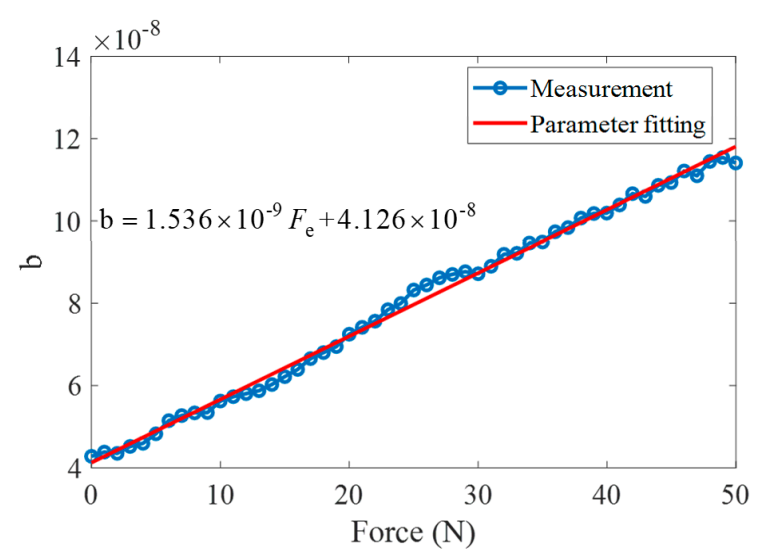

(b)

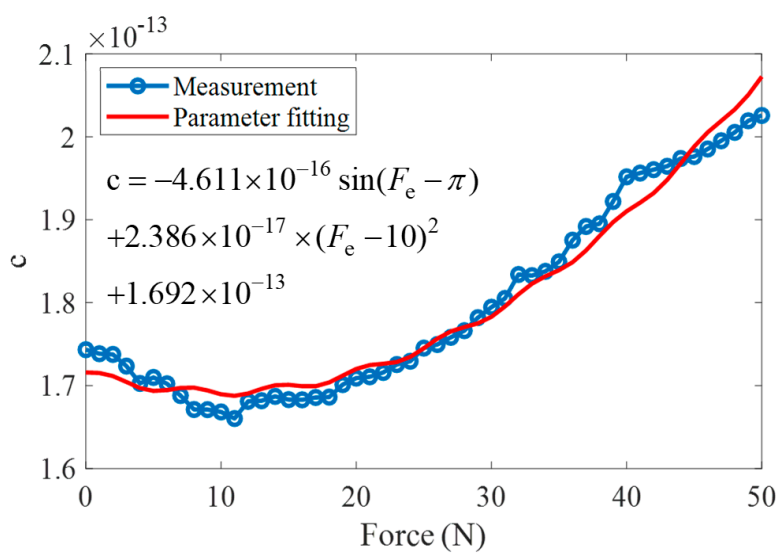

(c)

Figure 11. The estimated parameters of transfer function. (a) Parameter: a; (b) Parameter: b; (c) Parameter: c. 
After the calculation and parameter fitting process, the parameters in the impedance model of the transducer are obtained to establish the accurate dynamic impedance model. The dynamic impedance transfer function with external force is expressed as

$$
G(\mathrm{~s})=\frac{\left[\begin{array}{l}
\left(3.857 \times 10^{-11}-2.913 \times 10^{-12} \cos \left(0.0173 F_{\mathrm{e}}\right)-2.787 \times 10^{-12} \sin \left(0.0173 F_{\mathrm{e}}\right)\right) \mathrm{s}^{2} \\
+\left(1.536 \times 10^{-9} F_{\mathrm{e}}+4.126 \times 10^{-8}\right) \mathrm{s}+1
\end{array}\right]}{\left[\begin{array}{l}
C_{0} \mathrm{~s}\left(\left(3.857 \times 10^{-11}-2.913 \times 10^{-12} \cos \left(0.0173 F_{\mathrm{e}}\right)-2.787 \times 10^{-12} \sin \left(0.0173 F_{\mathrm{e}}\right)\right) \mathrm{s}^{2}\right. \\
+\left(1.536 \times 10^{-9} F_{\mathrm{e}}+4.126 \times 10^{-8}\right) \mathrm{s} \\
\left.-4.611 \times 10^{-16} \sin \left(F_{\mathrm{e}}-\pi\right)+2.386 \times 10^{-17} \times\left(F_{\mathrm{e}}-10\right)^{2}+1.692 \times 10^{-13}+1\right)
\end{array}\right]}
$$

To analyze the dynamic electrical response of ultrasonic transducer, the input voltage $U_{\mathrm{i}}$ is assumed as $10 \times \sin (\omega \mathrm{t}) \mathrm{V}$, the current response of ultrasonic transducer can be obtained in the closed-loop system (Figure 9) and Equation (21). The current responses of ultrasonic transducer are shown in Figure 12. It is observed that the peak current response of ultrasonic transducer without force factor in Equation (20) oscillates in the initialization time with different external forces, while the peak current response of ultrasonic transducer with force factor in Equation (22) rises smoothly and gets a greater value. Therefore, the dynamic impedance model is an important link of maintaining the ultrasonic transducer to work at its resonant state.

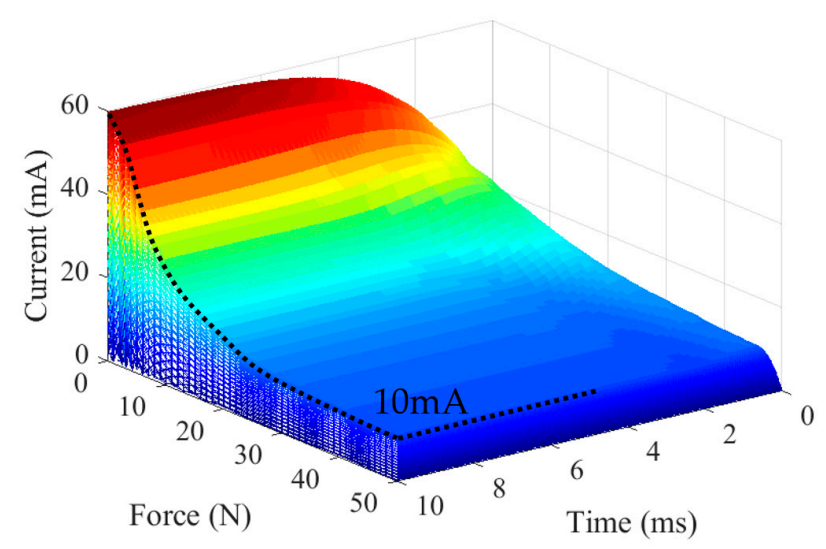

(a)

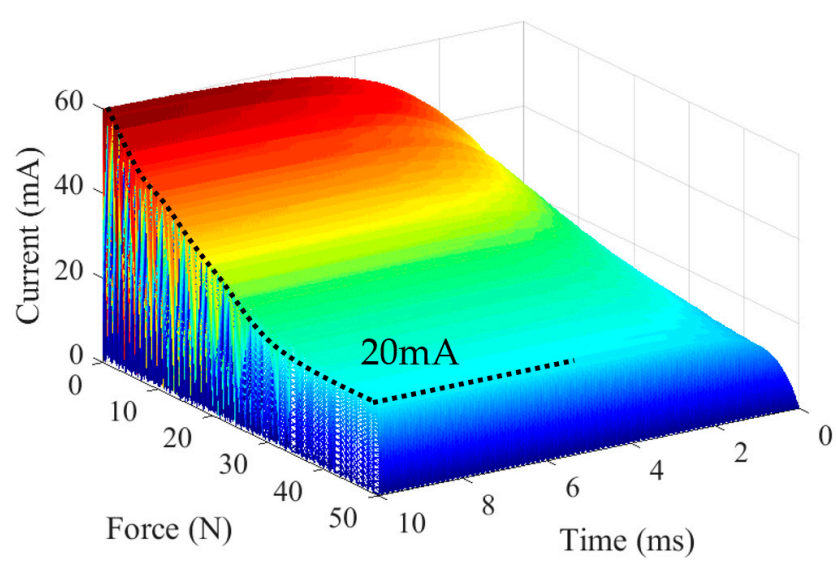

(b)

Figure 12. Current response of closed-loop system. (a) Current response without force factor; (b) Current response with force factor.

Through experiment and parameter fitting, it is found that the impedance transfer function of the transducer varies with the force. When the impedance model of the ultrasonic transducer is adopted 
as the control object, the variable load impedance transfer function should be considered into the resonant vibration control system.

\section{Conclusions}

In this work, an impedance model of the ultrasonic transducer in the ultrasonic machining is established. By using the electromechanical equivalent circuit method, the equivalent impedance of each component of the ultrasonic transducer is derived, and the assembled equivalent impedance model is studied. The impedance equivalent model is calculated and effectively predicts the frequency, susceptance and conductance of the ultrasonic transducer. The effects of the resonant frequency and impedance of the ultrasonic transducer with different tightening torques of clamping nut and various extension lengths of machining tool are analyzed. In the experiment, the impedance dynamic impedance model with external force is established to obtain dynamic characteristic of machining process.

Author Contributions: Methodology, writing, investigation, and editing, J.-G.Z.; conceptualization, project administration, funding acquisition, Z.-L.L.; resources and data curation, W.-J.M.; formal analysis and validation, G.H.-H.; review, Y.-M.L.

Funding: This work was supported by the following funds: (1) National Natural Science Foundation of China (U1713206), (2) Basic Research Plan of Shenzhen (JCYJ20170413112645981), and (3) Shenzhen Technology Innovation Program (JCYJ20170811160003571).

Conflicts of Interest: The authors declare no conflict of interest.

\section{References}

1. Kumar, J.; Khamba, J.S.; Mohapatra, S.K. An investigation into the machining characteristics of titanium using ultrasonic machining. Int. J. Mach. Mach. Mater. 2008, 3, 143-161. [CrossRef]

2. Singh, R.P.; Singhal, S. Rotary ultrasonic machining: A review. Adv. Manuf. Process. 2016, 31, 1795-1824. [CrossRef]

3. Wang, J.J.; Zhang, J.F.; Feng, P.F.; Ping, G. Damage formation and suppression in rotary ultrasonic machining of hard and brittle materials: A critical review. Ceram. Int. 2018, 44, 1227-1239. [CrossRef]

4. Wang, H.; Ning, F.D.; Hu, Y.B.; Cong, W.L. Surface grinding of CFRP composites using rotary ultrasonic machining: A comparison of workpiece machining orientations. Int. J. Adv. Manuf. Technol. 2018, 95, 2917-2930. [CrossRef]

5. Singh, R.P.; Singhal, S. Investigation of machining characteristics in rotary ultrasonic machining of alumina ceramic. Adv. Manuf. Process. 2016, 32, 309-326. [CrossRef]

6. Gao, C.Y.; Xiao, D.G.; Pan, Q.X.; Xu, C.G. Ultrasonic transducers frequency response study with equivalent circuit and finite element method. In Proceedings of the IEEE International Conference Mechatronics and Automation, Beijing, China, 7-10 August 2011; pp. 1746-1750.

7. Roh, Y.; Khuri-Yakub, B.T. Finite element modeling of capacitor micromachined ultrasonic transducers. In Proceedings of the IEEE Ultrasonics Symposium, San Juan, Puerto Rico, 22 October 2000; pp. 905-908.

8. Kuo, K.L. Design of rotary ultrasonic milling tool using FEM simulation. J. Mater. Process. Tech 2008, 201, 48-52. [CrossRef]

9. Abboud, N.N.; Wojcik, G.L.; Vaughan, D.K.; Mould, J.; Powell, D.J.; Nikodym, L. Finite element modeling for ultrasonic transducers. In Proceedings of the SPIE International Sumposium Medical Imaging 1998: Ultrasonic Transducer Engineering, San Diego, CA, USA, 16-21 February 1998; pp. 19-43.

10. Amir, A.; Abbas, P. Correct Prediction of the vibration behavior of a high power ultrasonic transducer by FEM simulation. Int. J. Adv. Manuf. Technol. 2008, 39, 21-28.

11. Long, Z.L.; Wu, Y.X.; Han, L.; Zhong, J. Dynamics of ultrasonic transducer system for thermosonic flip chip bonding. IEEE Trans. Compon. Packag. Technol. 2009, 32, 261-267. [CrossRef]

12. Chen, X.Z.; Yin, Y.X.; Hou, Q.W.; Jin, L.W.; Li, X.L. The simulation and structural optimization of ultrasonic transducer. In Proceedings of the International Conference on Industrial and Information Systems, Dalian, China, 10 July 2010; pp. 330-333. 
13. Saleem, A.; Salah, M.; Ahmad, N.; Siberschmidt, V. Control of ultrasonic transducers for machining applications. In Proceedings of the International Symposium on Mechatronics and Its Applications, Amman, Jordan, 11 April 2013.

14. Voronina, S.; Babitsky, V. Autoresonant control strategies of loaded ultrasonic transducer for machining applications. J. Sound Vib. 2018, 313, 395-417. [CrossRef]

15. Babitsky, V.I.; Astashev, V.K.; Kalashnikov, A.N. Autoresonant control of nonlinear mode in ultrasonic transducer for machining applications. Ultraosnics 2004, 42, 29-35. [CrossRef] [PubMed]

16. Wang, S.H.; Tsai, M.C. Dynamic modeling of thickness-mode piezoelectric transducer using the block diagram approach. Ultrasonics 2011, 51, 617-624. [CrossRef] [PubMed]

17. Sherrit, S.; Leary, S.P.; Dolgin, B.P.; Bar-Cohen, Y. Comparison of the Mason and KLM equivalent circuits for piezoelectric resonators in the thickness mode. In Proceedings of the IEEE Ultrasonics Symposium, Caesars Tahoe, NV, USA, 17 October 1999; pp. 921-926.

18. Smyth, K.; Kim, S.G. Experiment and simulation validated analytical equivalent circuit model for piezoelectric micromachined ultrasonic transducers. IEEE Trans. Ultrason. Ferroelectr. Freq. Control. 2015, 62, 744-765. [CrossRef] [PubMed]

19. Je, Y.; Ahn, H.; Been, K.; Moon, W.; Lee, H. An advanced equivalent circuit for a piezoelectric micromachined ultrasonic transducer and its lumped parameter measurement. In Proceedings of the IEEE Ultrasonics Symposium, Prague, Czech Republic, 21-25 July 2013; pp. 279-282.

20. Caronti, A.; Caliano, G.; Iula, A.; Pappalardo, M. An accurate model for capacitive micromachined ultrasonic transducers. IEEE Ultrason. Ferroelectr. Freq. Control Soc. 2002, 49, 159-168. [CrossRef]

21. Wang, F.J.; Zhang, H.J.; Liang, C.M.; Tian, Y.L.; Zhao, X.Y.; Zhang, D.W. Design of high-frequency ultrasonic transducers with flexure decoupling flanges for thermosonic bonding. IEEE Trans. Ind. Electron. 2016, 63, 2304-2312. [CrossRef]

22. Lin, S.Y.; Guo, H.; Xu, J. Actively adjustable step-type ultrasonic horns in longitudinal vibration. J. Sound Vib. 2018, 419, 367-379. [CrossRef]

23. Lin, S.Y. Radiation impedance and equivalent circuit for piezoelectric ultrasonic composite transducers of vibrational mode-conversion. IEEE Trans. Ultrason. Ferroelectr. Freq. Control 2012, 59, 139-149.

24. Sammoura, F.; Kim, S.G. Theoretical modeling and equivalent electric circuit of a bimorph piezoelectric micromachined ultrasonic transducer. IEEE Trans. Ultrason. Ferroelectr. Freq. Control. 2012, 59, 990-998. [CrossRef]

25. Dang, C.; Schmerr, W.; Sedov, A. Ultrasonic transducer sensitivity and model-based transducer characterization. Res. Nondestr. Eval. 2003, 14, 203-228. [CrossRef]

26. Milan, N.; Lenka, C. The effect of the shape parameters on modal properties of ultrasonic horn design for ultrasonic assisted machining. In Proceedings of the International DAAAM Baltic Conference, Tallinn, Estonia, 19-21 April 2012.

27. Nassar, S.; Veeram, A.B. Ultrasonic control of fastener tightening using varying wave speed. J. Press. Vessel Technol. 2006, 128, 189-198. [CrossRef]

28. Schomburg, W.K. Piezoelectric Effect; Springer: Berlin, Germany, 2011.

29. McBrearty, M.; Kim, L.H.; Bilgutay, N.M. Analysis of impedance loading in ultrasonic transducer systems. In Proceedings of the IEEE Ultrasonics Symposium, Chicago, IL, USA, 5 October 1998; pp. 497-502.

30. Salama, K.; Barber, G.C.; Chandrasekaran, N. Measurement of residual stress using the temperature dependence of ultrasonic velocity. In Proceedings of the IEEE Ultrasonics Symposium, San Diego, CA, USA, 27 October 1982; pp. 877-894.

31. Long, Z.L.; Zhang, J.G.; Wu, X.J.; Liu, Y.C.; Zhou, X.; Li, Z.H. Impedance modeling of ultrasonic transducers used in heavy aluminum wire bonding. IEEE Trans. Compon. Packag. Manuf. Technol. 2018, 8, 1107-1115. [CrossRef]

32. Mason, W.P. Electromechanical Transducers and Wave Filters; Van Nostrand: Princeton, NJ, USA, 1948.

(C) 2019 by the authors. Licensee MDPI, Basel, Switzerland. This article is an open access article distributed under the terms and conditions of the Creative Commons Attribution (CC BY) license (http:/ / creativecommons.org/licenses/by/4.0/). 